\title{
EDITORIALS
}

\section{Gene Expression Profile Testing in Skin Cancer Prognosis: The Data is Clear - It's Time to Get on Board}

\author{
Darrell S. Rigel, MD, MS ${ }^{1}$, Roger I. Ceilley, $\mathrm{MD}^{2}$, Graham H. Litchman, DO, $\mathrm{MS}^{3}$, \\ Clay J. Cockerell, MD ${ }^{4}$ \\ ${ }^{1}$ Clinical Professor of Dermatology, NYU Grossman School of Medicine, New York, NY \\ ${ }^{2}$ Clinical Professor of Dermatology, The University of lowa School of Medicine, lowa City, IA \\ ${ }^{3}$ Dermatology Resident, St. John's Episcopal Hospital, New York, NY \\ ${ }^{4}$ Clinical Professor of Dermatology and Pathology, University of Texas Southwestern Medical Center, Dallas, TX
}

Prognosis in skin cancer has traditionally been based on subjective clinical and histologic parameter-based systems, the most prominent of them being American Joint Committee on Cancer (AJCC) staging. "Early" melanomas have good outcomes and "advanced" cases have significant mortality and morbidity. However, clinical and pathological concordance and reproducibility remain low, suggesting that these subjective prognostic indicators fall below the limits of reliability in these staging schemata. ${ }^{1}$ For that reason, there have been calls to augment these traditional approaches using objective molecular and genetic techniques to improve the accuracy for the staging of skin cancer patients. ${ }^{2}$ A large number of independent, peer-reviewed studies evaluating gene expression profile tests have been published (see Table), yet transition of these molecular-based tests into clinical care has not been as rapid for cutaneous melanoma as might have been expected, based on the data. Here, we explore some of the non-scientific and political reasons why this may be the case.

Gene Expression Profile (GEP) prognostic testing was originally developed for uveal melanomas where its use has become standard-of-care. There are several versions of the test under development but the currently approved, most widely used and broadly validated cutaneous version of the test stratifies risk of metastasis through the assessment of the degree of expression of 31 genes related to melanoma progression. Its utility has been widely recognized by clinicians. Over 16,000 melanomas in the US were 31-GEP assessed in 2019.

Validity and utility of the 31-GEP test has been proven in a number of ways. The test has been directly validated for 5-year recurrence risk in retrospective and prospective studies including over 1,500 patients. Those studies demonstrated that the test accurately predicts metastasis risk independent of clinical and pathologic factors, with strong sensitivity and negative predictive value (NPV). Additionally, a significantly poorer prognosis has been observed for identified high-risk patients across all studies to date. Multivariate regression analysis has consistently shown independent and generally superior prognostic accuracy of the 31-GEP test compared to sentinel lymph node biopsy 
(SLNBx) and other clinicopathologic factors (Table).

31-GEP accuracy has also been positively reported in 2 recent systematic reviews/meta-analyses as meeting the highest standards for prognostic tools as described by the Strength of Recognition Taxonomy (SORT) system. ${ }^{3,4}$ The test has consistently improved upon the critical accuracy metrics of sensitivity and NPV over those assessed by clinicopathologic staging alone, including patients who were diagnosed with thin tumors, in published validation studies that have included nearly 2,700 patients. Given that some AJCC criteria are somewhat subjective and some (such as Breslow thickness) may be underestimated from sampling error, ${ }^{5}$ this may explain how the addition of the objective 31-GEP information to the AJCC system has been demonstrated to statistically significantly improve prognostic assessment beyond AJCC alone. ${ }^{6}$ The 31GEP test has also been shown to assess the probability of SLN positivity in T1-T2 lesions. ${ }^{7}$ In addition, studies have demonstrated that the integration of 31-GEP data into management evaluation influences management intensity appropriately. ${ }^{8}$

More importantly, because there are so many more SLNBX- than + patients and thin than thicker lesions, the absolute number of people who die in these aggregate "low-risk" groups are greater than in the high-risk groups identified through AJCC criteria alone. ${ }^{9}$ Studies have demonstrated that the 31-GEP test identifies high-risk melanoma patient subsets that are more likely to experience metastasis/death within low-risk patient groups who have SLNBx- disease, stage I to IIA tumors, and thin tumors. ${ }^{10}$

These findings have led to modification of the National Comprehensive Cancer
Network (NCCN) guidelines to recommend that GEP for melanoma can provide useful information on individual risk of recurrence as an adjunct to standard AJCC staging ${ }^{11}$ and been validated by the standards required for $\mathrm{CMS}$ for insurance coverage of the test in the Medicare population for evaluation of candidates for SLNBx.

Despite this overwhelming evidence, some have still raised objections to integrating this approach into melanoma management. ${ }^{12}$ Critics suggest that this test has not been FDA approved and therefore its validity has been questioned. However, as this test is not a drug or device, FDA approval is not required but the appropriate federal approval for this type of test (CLIA) was obtained. Their suggestion that all identified higherrisk thin melanoma patients will automatically have more intense follow-up regimens is also not supported by impact studies. Rather, these studies demonstrated that, like any clinical data, the additional information provided by 31-GEP testing was not blindly followed but was appropriately integrated as part of the overall management decision process. ${ }^{8}$ They derive "consensus" statements using only a $50 \%$ agreement threshold when this process typically requires a supermajority. They support a prognostic test (SLNBx) with significant morbidity but criticize the 31 -GEP test which has been shown in some studies to be prognostically superior with no morbidity. They ignore multiple prospective trials that have demonstrated efficacy and wrongly suggest that prospective randomized controlled trials are needed for validation when these are not required (or even possible to perform for prognostic tests as there is no way to interpret a control [nontested] group) for purely evaluating prognostic tests. ${ }^{13}$ 
Table. Representative clinical validity, utility and impact studies for the 31-GEP test for melanoma prognosis

\begin{tabular}{|c|c|c|c|c|}
\hline Clinical validity studies & $\begin{array}{l}\text { Study design; } \\
\text { objective }\end{array}$ & $\mathbf{N}$ & $\begin{array}{l}\text { Multivariate } \\
\text { Comparators }\end{array}$ & $\begin{array}{l}\text { GEP risk } \\
\text { (recurrence) }\end{array}$ \\
\hline $\begin{array}{l}\text { Greenhaw, J Am Acad Dermatol } \\
2020\end{array}$ & SR/MA & 1,479 & BT, U, SLNB, age & Class 2B HR=2.9** \\
\hline $\begin{array}{l}\text { Litchman, SKIN J Cut Medicine, } \\
2020\end{array}$ & SR/MA & 1,407 & BT, U, SLNB & Class $2 \mathrm{~B} \mathrm{HR}=7.2^{* *}$ \\
\hline Gastman, Head Neck 2019 & Archival; CV & 157 & BT, U, SLNB, MR & Class $2 \mathrm{HR}=3.0$ \\
\hline Gastman, J Am Acad Dermatol 2019 & Archival; CV & 690 & BT, U, SLNB, MR & Class $2 \mathrm{~B} \mathrm{HR}=2.92^{* *}$ \\
\hline Keller, Cancer Med 2019 & Prospective; CV & 159 & BT, U, SLNB, age & Class $2 \mathrm{HR}=9.2^{* *}$ \\
\hline $\begin{array}{l}\text { Podlipnik, J Eur Acad Dermatol } \\
\text { Venearol } 2019\end{array}$ & Prospective; $\mathrm{CV}$ & 86 & AJCC, age & Class $2 \mathrm{HR}=18.8^{*}$ \\
\hline Vetto, Future Oncol 2019 & Retrospective; CV, CU & 1,421 & $\mathrm{~N} / \mathrm{A}$ & $\mathrm{N} / \mathrm{A}$ \\
\hline Greenhaw, Dermatol Surg 2018 & Prospective; $\mathrm{CV}$ & 256 & $\mathrm{~N} / \mathrm{A}$ & Class 2 OR=22 \\
\hline Zager, BMC Cancer 2018 & Retrospective; CV & 523 & BT, U, SLNB, MR & Class $2 \mathrm{HR}=5.40^{* *}$ \\
\hline Hsueh, J Hematol Oncol 2017 & Prospective; $\mathrm{CV}, \mathrm{CU}$ & 322 & BT, U, SLNB, MR & Class $2 \mathrm{HR}=7.15^{*}$ \\
\hline Clinical utility studies & $\begin{array}{l}\text { Study design; } \\
\text { objective }\end{array}$ & $\mathrm{N}$ & $\begin{array}{l}\text { Modified } \\
\text { Surveillance }\end{array}$ & $\begin{array}{l}\text { Management change } \\
\text { rates }\end{array}$ \\
\hline Dillon, SKIN: J Cutan Med 2018 & Prospective; CU & 247 & FU, I, L & $49 \%$ \\
\hline Schuitevoerder, JDD 2018 & Retrospective, CU & 91 & FU, R, AT & $52 \%$ \\
\hline Berger, Curr Med Res Opin 2015 & Retrospective; CU & 156 & FU, I, L, R & $53 \%$ \\
\hline Clinical impact studies & Study design & $\mathrm{N}$ & Target groups & $\begin{array}{l}\text { Risk-appropriate } \\
\text { management impact }\end{array}$ \\
\hline Mirsky, J Drugs in Dermatol 2018 & $\begin{array}{l}\text { Patient vignette; } \\
\text { adjunctive testing }\end{array}$ & 164 & $\begin{array}{l}\text { Dermatology } \\
\text { NPs/PAs }\end{array}$ & Yes \\
\hline Svoboda, J Drugs in Dermatol 2018 & $\begin{array}{l}\text { Patient vignette; GEP } \\
\text { recommendations }\end{array}$ & 181 & Dermatologists & Yes \\
\hline Farberg, J Drugs in Dermatol 2017 & $\begin{array}{l}\text { Patient vignette; BT } \\
\text { inflection points; } \\
\text { adjunctive testing }\end{array}$ & 169 & $\begin{array}{l}\text { Dermatology } \\
\text { residents }\end{array}$ & Yes \\
\hline
\end{tabular}

Abbreviations: AT - Adjuvant therapy; BT - Breslow thickness; CMRO - Current Medical Research and Opinion; CU clinical utility; CV - clinical validity; FU - followup; HR - hazard ratio; I - imaging; JAAD - Journal of the American Academy of Dermatology; JEAVD - Journal of the European Academy of Dermatology and Venereology; L - laboratory workup; MR - mitotic rate; OR - odds ratio; R - referral; SLNB - sentinel lymph node biopsy; U - ulceration; * $\mathrm{p} \leq 0.01$; ${ }^{* *} \mathrm{p} \leq 0.0001 ;{ }^{\sharp}$ multivariate analysis was not performed in this study 
Consensus-based appropriate usage criteria for 31-GEP testing have been developed and published. ${ }^{14}$ Equally important to recognize is that 31-GEP testing is not for use in all lesions. Usage has not been validated with in-situ and stage IV melanomas nor for predicting patient response to therapies. In addition, melanomas with Breslow thickness $<0.3 \mathrm{~mm}$ may not benefit. ${ }^{15}$

Finally, the usage of GEP testing for skin cancer prognosis has now extended beyond melanoma. A 40-GEP test has shown early promise for assessing prognosis in patients with advanced cutaneous squamous cell carcinoma. ${ }^{16}$

There have now been over 20 independent peer-reviewed data-driven studies demonstrating consistent clinical validity, efficacy, and positive impact of the 31-GEP test. Given this strong existing supportive published evidence, discounting the value of GEP testing based on hypothetical models, inter-specialty competition with concerns regarding personal adverse economics or personal biases/conflicts for those that may be developing competitive methodologies leading to the subjective/hypothetical defining of "harm" for patients is not data justified.

An objective review of published data clearly demonstrates that we have now reached the point where, given the evidence, GEP testing for melanoma prognosis is long beyond the suggestion that it is just for "experimental" usage. It's time for this debate to be concluded so that our patients can benefit. The train has left the station. It's time to get on board.
Conflict of Interest Disclosures: Dr. Rigel has served on an advisory board, has been an investigator, and has received honoraria from Castle Biosciences. Dr. Ceilley has served on an advisory board for Castle Biosciences. Dr. Litchman has no relevant disclosures or conflicts of interest. Dr. Cockerell has served as a consultant for Castle Biosciences.

Funding: None

Corresponding Author:

Darrell S. Rigel, MD, MS

$35 \mathrm{E}$ 35th St. \#208

New York, NY 10016

Phone: 212-684-4542

Email: Darrell.rigel@gmail.com

References:

1. Elmore JG, Elder DE, Barnhill RL, et al. Concordance and Reproducibility of Melanoma Staging According to the 7th vs 8th Edition of the AJCC Cancer Staging Manual. JAMA Netw Open. 2018;1(1):e180083. doi:10.1001/jamanetworkopen.2018.0083

2. Ferguson PM, Gershenwald JE, Scolyer RA. Staging of Cutaneous Melanoma: Is There Room for Further Improvement? JAMA Netw Open. 2018;1(1):e180086. doi:10.1001/jamanetworkopen.2018.0086

3. Greenhaw BN, Covington KR, Kurley SJ, Yeniay Y, Cao NA, Plasseraud KM, Cook RW, Hsueh EC, Gastman BR, Wei ML, Molecular risk prediction in cutaneous melanoma: a metaanalysis of the 31-gene expression profile prognostic test in 1,479 patients, Journal of the American Academy of Dermatology (2020), doi.org/10.1016/j.jaad.2020.03.053.

4. Litchman G, Prado G, Teplitz R, Rigel DS. A Systematic Review and Meta-Analysis of Gene Expression Profiling for Primary Cutaneous Melanoma Prognosis. SKIN J Cutan Med, 2020 May vol 4(3):221-237. doi: 10.25251/skin.4.3.3

5. Bax MJ, Johnson TM, Harms PW, Schwartz JL, Zhao L, Fullen DR, Chan MP. Detection of Occult Invasion in Melanoma In Situ. JAMA Dermatol. 2016 Nov 1;152(11):1201-1208. doi: 10.1001/jamadermatol.2016.2668.

6. Ferris LK, Farberg AS, Middlebrook B, Johnson CE, Lassen N, Oelschlager KM, Maetzold DJ, Cook RW, Rigel DS, Gerami P. Identification of high-risk cutaneous melanoma tumors is improved when combining the online American

July 2020 Volume 4 Issue 4 
Joint Committee on Cancer Individualized Melanoma Patient Outcome Prediction Tool with a 31-gene expression profile-based classification. J Am Acad Dermatol. 2017 May;76(5):818825.e3. doi: 10.1016/j.jaad.2016.11.051.

7. Vetto JT, Hsueh EC, Gastman BR, Dillon LD, Monzon FA, Cook RW, Keller J, Huang X, Fleming A, Hewgley P, Gerami P, Leachman S, Wayne JD, Berger AC, Fleming MD. Guidance of sentinel lymph node biopsy decisions in patients with T1-T2 melanoma using gene expression profiling. Future Oncol. 2019 Apr;15(11):12071217. doi:10.2217/fon-2018-0912.

8. Farberg AS, Glazer AM, White R, Rigel DS. Impact of a 31-gene Expression Profiling Test for Cutaneous Melanoma on Dermatologists' Clinical Management Decisions. J Drugs Dermatol. 2017;16(5):428-431.

9. Landow SM, Gjelsvik A, Weinstock MA. Mortality burden and prognosis of thin melanomas overall and by subcategory of thickness, SEER registry data, 1992-2013. J Am Acad Dermatol. 2017 Feb;76(2):258-263. doi: 10.1016/j.jaad.2016.10.018. Epub 2016 Nov 22.

10. Gastman B, Gerami P, Kurley S, Cook R, Leachman S, Vetto J. Identification of patients at risk of metastasis using a prognostic 31-gene expression profile in subpopulations of melanoma patients with favorable outcomes by standard criteria. J Am Acad Dermatol 2019;80:149-57.

11. Swetter SM, et. al. NCCN Clinical Practice Guidelines in Oncology: Cutaneous Melanoma. April 9, 2020. National Comprehensive Cancer Network; 2020.

12. Kovarik C, Chu E, Adamson A. Gene Expression Profile Testing for Thin Melanoma; Evidence to Support Clinical Use Remains Thin. JAMA Dermatol 2020 Online publication.

13. Mathes T, Pieper D. An algorithm for the classification of study designs to assess diagnostic, prognostic and predictive test accuracy in systematic reviews. Systematic Reviews. 2019 Sep;8(1):226. DOI: 10.1186/s13643-019-1131-4.

14. Berman, B., Ceilley, R., Cockerell, C., Ferris, L., High, W., Lebwohl, M., Nestor, M., Rosen, T., Litchman, G., Prado, G., Svoboda, R., \& Rigel, D. (2019). Appropriate Use Criteria for the Integration of Diagnostic and Prognostic Gene Expression Profile Assays into the Management of Cutaneous Malignant Melanoma: An Expert Panel Consensus-Based Modified Delphi Process Assessment. SKIN The Journal of Cutaneous Medicine, 2019;3(5), 291-306. doi:https://doi.org/10.25251/skin.3.5.1
15. Marks, E., Caruso, H., Kurley, S., Ibad, S., Plasseraud, K., Monzon, F., \& Cockerell, C. (2019). Establishing an evidence-based decision point for clinical use of the 31-gene expression profile test in cutaneous melanoma. SKIN The Journal of Cutaneous Medicine, 2019;3(4), 239249. doi:https://doi.org/10.25251/skin.3.4.2

16. Wysong A, Newman JG, Covington KR, Kurley SJ, Ibrahim SF, Farberg AS, Bar A, Cleaver NJ, Somani AK, Panther D, Brodland DG, Zitelli J, Toyohara J, Maher IA, Xia Y, Bibee K, Griego R, Rigel DS, Plasseraud KM, Estrada S, Sholl LM, Johnson C, Cook RW, Schmults CD, Arron ST. Validation of a 40-Gene Expression Profile Test to Predict Metastatic Risk in Localized High-Risk Cutaneous Squamous Cell Carcinoma. J Am Acad Dermatol. 2020 Apr 25. pii: S01909622(20)30704-0. doi:10.1016/j.jaad.2020.04.088. 